\title{
Rate of Growth For Library Collections
}

\begin{abstract}
A table is given to show conveniently up to a twenty-year interval and/or a doubling of the collection the annual rate of growth of any library collection, given the growth period in years and the size of the collection at the beginning and end of this period. A formula for determining solutions beyond the limits of the table is also derived and illustrated.
\end{abstract}

\section{E}

\section{THE BACKGROUND} in the United States, over three centuries ago, their collections have on the average been doubling in size every sixteen years. When these libraries were small, their librarians did not worry particularly about the rate of growth of their collections. But about the time of the Second World War, as building, and hence storage, costs increased, Rider and others sounded the alarm. ${ }^{1}$ The problem has been exacerbated by the current squeeze on public funds. Academic and research librarians are by now tired of hearing, and are only too aware, that their collections are increasing at a geometrical, rather than at an arithmetical, rate.

Since an approximately constant (exponential) rate of growth represents the true state of affairs, it is of value to librarians planning building needs or engaging in other research involving comparisons and predictions of collection growth, to know the rate of growth for given situations. The accompanying table gives this result directly for peri-

Fred Heinritz is a professor at Southern Connecticut University. ods up to twenty years, saving the need for laborious computation.

\section{USE OF THE TABLE}

The only data needed to use the table are the number of years covered $(\mathrm{T})$, and the size of the collection at the beginning $(\mathrm{P})$ and end $(\mathrm{A})$ of this period. As an example of use, suppose that a collection has grown from $1,000,000$ to $1,700,000$ volumes over eight years. $\mathrm{A} / \mathrm{P}=1.700$. The answer lies at the intersection of the 1.700 row and the 08 column. This value, 0.069 , represents an annual growth rate of 6.9 percent.

\section{Extension of THE TABLE}

For time periods exceeding twenty years and/or $\mathrm{A} / \mathrm{P}$ values exceeding 2.000 , the rate of growth may be calculated by the following formula. (For the derivation, see the Mathematical Note.)

$$
\begin{aligned}
& \text { Annual Rate of Growth }= \\
& \text { Antilog }\left[\frac{\log (\mathrm{A} / \mathrm{P})}{\mathrm{T}}\right]-1
\end{aligned}
$$

For example, if a library grows from 136,260 to 874,999 volumes over a forty year period, the annual rate of growth is 4.76 percent. $^{2}$ The calculations are: 
TABLE 1

annual Rate of Growth of a Library Collection over T Years, BegrnNing with P and ENDINg with A ITEMS

\begin{tabular}{|c|c|c|c|c|c|c|c|c|c|c|}
\hline & & & & & $T$ & & & & & \\
\hline$A / P \quad I$ & 02 & 04 & 06 & 08 & 10 & 12 & 14 & 16 & 18 & 20 \\
\hline 1.0501 & 0.025 & 0.012 & 0.008 & 0.006 & 0.005 & 0.004 & 0.003 & 0.003 & 0.003 & 0.002 \\
\hline 1.1001 & 0.049 & 0.024 & 0.016 & 0.012 & 0.010 & 0.008 & 0.007 & 0.006 & 0.005 & 0.005 \\
\hline 1.1501 & 0.072 & 0.036 & 0.024 & 0.018 & 0.014 & 0.012 & 0.010 & 0.009 & 0.008 & 0.007 \\
\hline 1.2001 & 0.095 & 0.047 & 0.031 & 0.023 & 0.018 & 0.015 & 0.013 & 0.011 & 0.010 & 0.009 \\
\hline 1.2501 & 0.118 & 0.057 & 0.038 & 0.028 & 0.023 & 0.019 & 0.016 & 0.014 & 0.012 & 0.011 \\
\hline 1.3001 & 0.140 & 0.068 & 0.045 & 0.033 & 0.027 & 0.022 & 0.019 & 0.017 & 0.015 & 0.013 \\
\hline 1.3501 & 0.162 & 0.078 & 0.051 & 0.038 & 0.030 & 0.025 & 0.022 & 0.019 & 0.017 & 0.015 \\
\hline 1.4001 & 0.183 & 0.088 & 0.058 & 0.043 & 0.034 & 0.028 & 0.024 & 0.021 & 0.019 & 0.017 \\
\hline 1.4501 & 0.204 & 0.097 & 0.064 & 0.048 & 0.038 & 0.031 & 0.027 & 0.023 & 0.021 & 0.019 \\
\hline 1.5001 & 0.225 & 0.107 & 0.070 & 0.052 & 0.041 & 0.034 & 0.029 & 0.026 & 0.023 & 0.020 \\
\hline 1.5501 & 0.245 & 0.116 & 0.076 & 0.056 & 0.045 & 0.037 & 0.032 & 0.028 & 0.025 & 0.022 \\
\hline $\begin{array}{l}1.6001 \\
1.6501\end{array}$ & 0.265 & 0.125 & $\begin{array}{l}0.081 \\
0.087\end{array}$ & 0.061 & 0.048 & 0.040 & 0.034 & 0.030 & 0.026 & 0.024 \\
\hline$\frac{1.0201}{1.7001}$ & $\frac{285}{304}$ & $\frac{0.133}{0.142}$ & 0.092 & $\frac{0.065}{0.069}$ & $\frac{0.051}{0.054}$ & 0.045 & $\frac{0.036}{0.039}$ & & 0.028 & $\begin{array}{l}25 \\
27\end{array}$ \\
\hline 1.7501 & 0.323 & 0.150 & 0.098 & 0.072 & 0.058 & 0.048 & 0.041 & 0.036 & $\begin{array}{l}0.030 \\
0.032\end{array}$ & 0.028 \\
\hline 1.8001 & 0.342 & 0.158 & 0.103 & 0.076 & 0.061 & 0.050 & 0.043 & 0.037 & 0.033 & 0.030 \\
\hline 1.8501 & 0.360 & 0.166 & 0.108 & 0.080 & 0.063 & 0.053 & 0.045 & 0.039 & 0.035 & 0.031 \\
\hline 1.9001 & 0.378 & 0.174 & 0.113 & 0.084 & 0.066 & 0.055 & 0.047 & 0.041 & 0.036 & 0.033 \\
\hline 1.9501 & 0.396 & 0.182 & 0.118 & 0.087 & 0.069 & & 0.049 & 0.043 & 0.038 & 0.034 \\
\hline 2.0001 & 0.414 & 0.189 & 0.122 & 0.091 & 0.072 & 0.059 & 0.051 & 0.044 & 0.039 & 0.035 \\
\hline
\end{tabular}

A. R. of G.

$$
\begin{aligned}
& =\text { Antilog }\left[\frac{\log (874,999 / 136,260)}{40}\right]-1 \\
& =\text { Antilog }\left[\frac{\log (6.4215)}{40}\right]-1 \\
& =\text { Antilog }\left[\frac{0.80763}{40}\right]-1 \\
& =\text { Antilog }[0.02019]-1 \\
& =1.0476-1 \\
& =0.0476
\end{aligned}
$$

\section{Mathematical Note}

The mathematics for a constant rate of growth is identical to that for compound interest. Thus the problem is, given $\mathrm{A}, \mathrm{P}$, and $\mathrm{T}$, to solve

$$
A=P(1+i)^{T}
$$

for i. For both sides of the equation
(1) take the logarithm, (2) subtract log $\mathrm{P}$, (3) divide by $\mathrm{T},(4)$ take the antilogarithm, (5) subtract one. This gives us

$$
\mathrm{i}=(\mathrm{A} / \mathrm{P})^{1 / \mathrm{T}}-1
$$

which for computational purposes is more conveniently expressed as

$$
i=\operatorname{Antilog}\left[\frac{\log (\mathrm{A} / \mathrm{P})}{\mathrm{T}}\right]-1
$$

\section{REFERENCES}

1. Fremont Rider, The Scholar and the Future of the Research Library; A Problem and Its Solution (New York: Hadham Press, 1944).

2. J. Periam Danton, Book Selection and Collections; A Comparison of German and American University Libraries (New York: Columbia Univ. Pr., 1963), p.103. 